\title{
Isolation and partial characterization of an $\mathrm{N}$-acetylgalactosamine-specific lectin from winter-aconite (Eranthis hyemalis) root tubers
}

\author{
Bruno P. CAMMUE,* Ben PEETERS $\dagger$ and Willy J. PEUMANS* $\ddagger$ \\ *Laboratorium voor Plantenbiochemie, Katholieke Universiteit Leuven, Kardinaal Mercierlaan 92, \\ B-3030 Leuven (Heverlee), Belgium, and †Laboratorium voor Humane Biologie, Katholieke Universiteit \\ Leuven, Universitair Ziekenhuis Gasthuisberg, Herestraat 49, B-3030 Leuven (Heverlee), Belgium
}

(Received 26 November 1984 ; accepted 11 January 1985)

\begin{abstract}
A lectin was isolated from root tubers of winter aconite (Eranthis hyemalis) by affinity chromatography on fetuin-agarose, and it was partially characterized with respect to its biochemical, physicochemical and carbohydrate-binding properties. The Eranthis hyemalis lectin is a dimeric protein $\left(M_{\mathrm{r}} 62000\right)$ composed of two different subunits of $M_{\mathrm{r}} 30000$ and 32000 , held together by disulphide bonds. It is especially rich in asparagine/aspartic acid, glutamine/glutamic acid and leucine, and contains $5 \%$ covalently bound carbohydrate. Hapten inhibition assays indicated that the winteraconite lectin is specific for $\mathrm{N}$-acetylgalactosamine. In addition, the lectin exhibits a pronounced specificity towards blood-group-O erythrocytes. The winter-aconite lectin is the first lectin to be isolated from a species belonging to the plant family Ranunculaceae. It appears to be different from all previously described plant lectins.
\end{abstract}

At present, over 100 plant lectins have been isolated and characterized with respect to their biochemical and molecular structure and carbohydrate-specificity (Goldstein \& Hayes, 1978). In the past, lectins have mostly been studied in dry seeds, and especially in seeds of legumes. However, during the last few years, increasing interest has been drawn to lectins occurring in various types of vegetative tissues of a number of plant species. Well-known examples of typical non-seed lectins are the tuber, leaf and fruit lectins from Solanaceae species (Allen et al., 1978; Kilpatrick, 1980), phloem lectins from Cucurbitaceae species (Sabnis \& Hart, 1978; Allen, 1979), root lectins from pokeweed (Phytolacca americana) (Waxdal, 1974) and white bryony (Bryonia dioica) (Peumans et al., 1984) and bark lectins from black locust (Robina pseudoacacia) (Horejsi et al., 1978) and elder (Sambucus nigra) (Broekaert et al., 1984).

In the present paper we describe the isolation and partial characterization of an $\mathrm{N}$-acetylgalactosamine-specific lectin from root tubers of winter aconite (Eranthis hyemalis), a representative of the plant family Ranunculaceae.

Abbreviations used: EHL, Eranthis hyemalis lectin; PBS, phosphate-buffered saline $\left[1.5 \mathrm{~mm}-\mathrm{KH}_{2} \mathrm{PO}_{4}\right]$ $\left.10 \mathrm{~mm}-\mathrm{Na}_{2} \mathrm{HPO}_{4}(\mathrm{pH} 7.4) / 3 \mathrm{~mm}-\mathrm{KCl} / 140 \mathrm{~mm}-\mathrm{NaCl}\right]$.

$\ddagger$ To whom correspondence should be addressed.

\section{Materials and methods}

\section{Materials}

Winter-aconite plants were collected locally in March and the tubers were either used immediately or stored at $-20^{\circ} \mathrm{C}$.

All reagents used were analytical grade. Fetuinagarose was obtained from Sigma Chemical Co. (St. Louis, MO, U.S.A.)

\section{Extraction and purification of the lectin}

Winter-aconite tubers $(20 \mathrm{~g})$ were cut into small pieces and homogenized with a mixer in $250 \mathrm{ml}$ of ice-cold PBS containing $5 \mathrm{~mm}$-thiourea. After being left on ice for $30 \mathrm{~min}$, the homogenate was decanted and the settled slurry re-extracted by mixing in another $250 \mathrm{ml}$ of ice-cold PBS. Then both fractions were combined, stirred for $1 \mathrm{~h}$ in the cold and centrifuged $(10000 \mathrm{~g}, 10 \mathrm{~min})$. The resulting supernatant was decanted and frozen overnight at $-80^{\circ} \mathrm{C}$. After thawing, the material that coagulated during freezing was spun down by centrifugation $(10000 \mathrm{~g}, 10 \mathrm{~min})$ and the resulting supernatant was taken off and filtered through filter paper (Whatman 3MM) (to remove any particulate material). Then the clear filtrate was applied to a column ( $5 \mathrm{ml}$ bed volume) of fetuinagarose equilibrated with PBS. Unbound protein was eluted by washing the column with PBS and 
$1 \mathrm{M}-\mathrm{NaCl}$ consecutively until the $A_{280}$ fell below 0.01 . Finally the bound lectin was desorbed with distilled water (Fig. 1a). It is worth mentioning that lactose (which, as is discussed below, is an efficient inhibitor of the agglutination activity of the winter-aconite lectin) did not desorb the lectin even when applied at a concentration as high as $0.3 \mathrm{M}$. Since other lectins such as elder bark lectin
(Broekaert et al., 1984) and Bryonia dioica agglutinin (Peumans et al., 1984) could easily be desorbed from the same column with lactose, the unusual behaviour of the winter-aconite lectin is, most probably, an intrinsic property of this lectin.

To ensure the purity of the Eranthis hyemalis lectin (EHL), the affinity-purified lectin was further purified by hydroxyapatite and ion-ex-
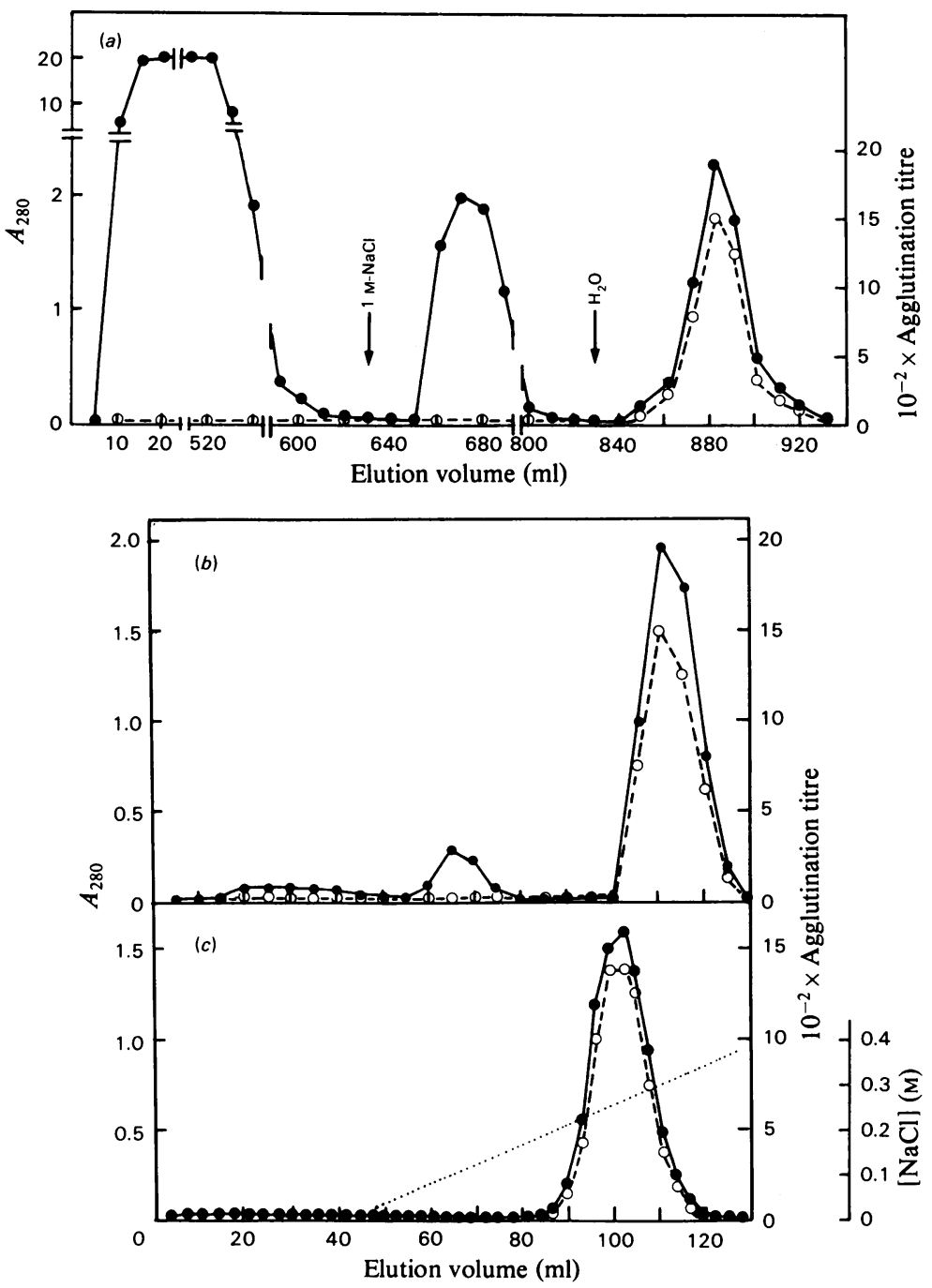

Fig. 1. Affinity chromatography (a), hydroxyapatite chromatography (b) and DEAE-Bio-Gel ion-exchange chromatography (c) of $E H L$

(a) Crude extract from the tubers $(20 \mathrm{~g}$ fresh wt. homogenized in $500 \mathrm{ml}$ of PBS containing $5 \mathrm{mM}$-thiourea) was applied to a fetuin-agarose column ( $5 \mathrm{ml}$ bed volume). Unbound protein was eluted with PBS and $\mathrm{NaCl}$ ( $1 \mathrm{M}$ ) until the $A_{280}$ fell below 0.01 , and the lectin was desorbed with distilled water. (b) Affinity-purified lectin was loaded on to a hydroxyapatite column $(10 \mathrm{ml}$ bed volume). Unbound impurities were washed off with $0.5 \mathrm{M}-\mathrm{NaCl}$, and the lectin was eluted with 0.3 M-potassium phosphate buffer, $\mathrm{pH}$ 7.2. (c) Peak fractions of EHL from the hydroxyapatite column were applied to a column of DEAE-Bio-Gel ( $10 \mathrm{ml}$ bed volume). After the column had been washed with $10 \mathrm{mM}-\mathrm{Tris} / \mathrm{HCl}$ buffer, $\mathrm{pH} 8.7$, the lectin was eluted with a salt gradient $(0-0.4 \mathrm{M}-\mathrm{NaCl}$ in the same Tris buffer). $-\bigcirc, A_{280} ; \mathrm{O}^{--} \mathrm{O}$, agglutination titre; $\cdots . . ., \mathrm{NaCl}$ gradient. 
change chromatography. The lectin-containing fractions desorbed from the fetuin-agarose were applied to a column ( $10 \mathrm{ml}$ bed volume) of hydroxyapatite (granular 80-200-mesh ASTM; Merck, Darmstadt, Germany) equilibrated with distilled water. Unbound impurities were washed off with $0.5 \mathrm{M}-\mathrm{NaCl}$, until the $A_{280}$ fell below 0.01 . Then the lectin was eluted with $0.3 \mathrm{M}$-potassium phosphate buffer, pH7.2 (Fig. 1b), dialysed against $10 \mathrm{~mm}$ Tris/HCl buffer, pH 8.7, and applied to a column ( $10 \mathrm{ml}$ bed volume) of DEAE-Bio-Gel (Bio-Rad Laboratories, Richmond, CA, U.S.A.) equilibrated with $10 \mathrm{mM}$-Tris/HCl buffer, $\mathrm{pH}$ 8.7. After the column had been washed with the same buffer, the lectin was eluted with a linear gradient $(50 \mathrm{ml})$ of $0-0.4 \mathrm{M}-\mathrm{NaCl}$ in $10 \mathrm{mM}$-Tris/ $\mathrm{HCl}$ buffer, $\mathrm{pH} 8.7$ (Fig. 1c). Peak fractions were collected, dialysed against PBS and used immediately or stored at $-20^{\circ} \mathrm{C}$.

The yield and efficiency of the purification procedure are summarized in Table 1.

\section{Agglutination assays}

Agglutination assays were carried out, in small glass tubes, in a final volume of $0.1 \mathrm{ml}$ containing $80 \mu \mathrm{l}$ of a $1 \%$ suspension of untreated or trypsintreated erythrocytes and $20 \mu 1$ of crude extracts or lectin solutions (each serially diluted with 2-fold increments). Agglutination was monitored visually after the tubes had been left for $1 \mathrm{~h}$ at room temperature.

\section{Analytical methods}

Protein was determined by the method of Lowry et al. (1951), with bovine serum albumin as standard.

Total neutral sugar was determined by the phenol/ $\mathrm{H}_{2} \mathrm{SO}_{4}$ method (Dubois et al., 1956), with D-glucose as standard. Amino sugars in a hydrolysed sample were determined in an amino acid analyser.
Sodium dodecyl sulphate/polyacrylamide-gel electrophoreis was performed with a discontinuous system (Laemmli, 1971) on $12.5-25 \%-(w / v)$-acrylamide gradient gels.

\section{Amino acid analysis}

Lectin samples were hydrolysed (in sealed glass tubes under an $\mathrm{N}_{2}$ atmosphere) for 24,48 and $72 \mathrm{~h}$ at $110^{\circ} \mathrm{C}$ in $6 \mathrm{M}$ - $\mathrm{HCl}$ containing $0.02 \% 2$-mercaptoethanol. After hydrolysis, $\mathrm{HCl}$ was removed by evaporation, and the residue was dissolved in sodium citrate buffer, $\mathrm{pH}$ 1.9. Amino acid analysis was done with a Biotronik LC 2000 amino acid analyser. This apparatus allows a separation of all 20 amino acids on a single column of Durrum resin, by using an elution program consisting of four different buffers. Amino acids were directly quantified by using an Infotronics integrator. Tryptophan was determined after hydrolysis with $3 \mathrm{M}$-mercaptoethanesulphonic acid. Cysteine was determined as cysteic acid after hydrolysis in performic acid.

\section{Results}

Occurrence, agglutination properties and carbohydrate-specificity of the lectin in winter-aconite tubers

Crude extracts from winter-aconite tubers were found to exhibit a reasonable agglutination activity. Preliminary experiments indicated that the lectin is blood-group-O-specific, since titres obtained with erythrocytes of that blood group are about 10 times those obtained with group- $A$ and group-B erythrocytes (Table 2 ). The carbohydratespecificity of the agglutinin in crude extracts was determined by hapten inhibition tests with a series of simple sugars ( $\mathrm{N}$-acetylgalactosamine, galactose, glucose, $\mathrm{N}$-acetylglucosamine, galactosamine, glucosamine, lactose, melibiose, fucose, arabinose, ribose, fructose, trehalose, sorbose,

Table 1. Purification of EHL

The procedure started from $20 \mathrm{~g}$ of winter-aconite tubers, homogenized in $2 \times 250 \mathrm{ml}$ of PBS. Further details are given in the Materials and methods section. One unit of agglutination activity corresponds to the amount of lectin required for agglutination of $1 \mathrm{ml}$ of trypsin-treated human blood-group-O erythrocytes.

\begin{tabular}{|c|c|c|c|c|c|}
\hline Purification step & $\begin{array}{l}\text { Volume } \\
\text { (ml) }\end{array}$ & $\begin{array}{l}\text { Total protein } \\
\text { (mg) }\end{array}$ & $\begin{array}{l}\text { Total agglutination } \\
\text { activity (units) }\end{array}$ & $\begin{array}{l}\text { Specific agglutination } \\
\text { activity (units/mg } \\
\text { of protein) }\end{array}$ & $\begin{array}{c}\text { Recovery } \\
(\%)\end{array}$ \\
\hline Crude extract & 500 & 924 & 200000 & 216 & 100 \\
\hline Freezing $\left(-80^{\circ} \mathrm{C}\right)$ & 500 & 749 & 200000 & 267 & 100 \\
\hline $\begin{array}{l}\text { Affinity chromatography on } \\
\text { fetuin-agarose }\end{array}$ & 50 & 27.8 & 180000 & 6471 & 90 \\
\hline Hydroxyapatite chromatography & 25 & 22.5 & 160000 & 7111 & 80 \\
\hline Ion-exchange chromatography & 36 & 19.1 & 140000 & 7330 & 70 \\
\hline
\end{tabular}

Vol. 227 
Table 2. Blood-group-specificity of crude tuber extract and purified EHL

The crude extract was prepared by homogenizing tuber tissue in $5 \mathrm{vol}$. (w/v) of PBS. Specific activity is expressed as the minimal concentration (in $\mu \mathrm{g} / \mathrm{ml}$ ) required for agglutination.

\begin{tabular}{cccc} 
Titre of crude extract & $\begin{array}{c}\text { Specific activity of purified EHL } \\
\text { with trypsin-treated } \\
\text { human erythrocytes }\end{array}$ & $\begin{array}{c}\text { With untreated } \\
\text { human erythrocytes }\end{array}$ & $\begin{array}{c}\text { With trypsin-treated } \\
\text { human erythrocytes }\end{array}$ \\
\hline A & 200 & 100 & 1 \\
B & 200 & 100 & 1 \\
O & 2000 & 10 & 0.1
\end{tabular}

Table 3. Carbohydrate-binding specificity of EHL in crude extract and purified preparations Agglutination activity was assayed with trypsin-treated human blood-group-O erythrocytes. The agglutination titre of the crude extract was 10 (which corresponds to a lectin content of about $1 \mu \mathrm{g} / \mathrm{ml}$ ).

Minimal concentration required for $50 \%$ inhibition of agglutination (mM)

\begin{tabular}{lcc}
\cline { 2 - 3 } Carbohydrate & With crude tuber extract & With purified EHL $(1 \mu \mathrm{g} / \mathrm{ml})$ \\
\hline$N$-Acetylgalactosamine & 0.25 & 0.25 \\
Lactose & 1.0 & 1.0 \\
Galactose & 2.0 & 2.0 \\
Melibiose & 3.0 & 3.0 \\
Fucose & 6.0 & 6.0 \\
Ribose & 9.5 & 9.5 \\
Arabinose & 11.5 & 11.5 \\
Raffinose & 12.5 & 12.5 \\
Galactosamine & 16.0 & 16.0 \\
Fetuin & $100^{*}$ & $100^{*}$
\end{tabular}

* Results expressed in $\mu \mathrm{g} / \mathrm{ml}$.

xylose, sucrose, maltose, sorbitol and mannose). As shown in Table 3, $N$-acetylgalactosamine was the best inhibitor, being respectively 4,8 and 12 times as potent as lactose, galactose and melibiose. Fucose, ribose, arabinose, raffinose and galactosamine also inhibited the agglutination, but only at higher concentrations. The agglutination of tuber extract was also efficiently inhibited by fetuin $(0.1 \mathrm{mg} / \mathrm{ml})$.

\section{Purification of EHL}

EHL could be purified by affinity chromatography on fetuin-agarose. The lectin was quantitatively bound (Fig. $1 a$ ) and could easily be desorbed with distilled water. Further purification by hydroxyapatite and ion-exchange chromatography yielded a homogeneous preparation. As shown in Table 1, the yield is about $1 \mathrm{mg} / \mathrm{g}$ of tuber tissue (on a fresh-weight basis). Taking into consideration an overall yield of $70 \%$ (Table 1), EHL represents about $3 \%$ of the total soluble protein in the crude extract. Since in extracts from other parts of the plants no agglutination activity could be detected, EHL has to be considered as a tuber-specific protein.

\section{Molecular structure of EHL}

Purified EHL was analysed by sodium dodecyl sulphate/polyacrylamide-gel electrophoresis both in the presence and in the absence of $2 \%(v / v) 2-$ mercaptoethanol. As shown in Fig. 2, non-reduced EHL migrated as a single band of $M_{\mathrm{r}} 62000$, whereas the reduced protein yielded two bands of $M_{\mathrm{r}} 30000$ and 32000 (indicating that the lectin molecules are built up of two different types of subunits, held together by disulphide bonds).

The $M_{\mathrm{r}}$ of native EHL was estimated by gel filtration and sucrose-density-gradient centrifugation. As shown in Fig. 3, both centrifugation and gel filtration indicated an $M_{\mathrm{r}}$ of about 60000 . It therefore appears that EHL is a dimeric molecule composed of two different subunits held together by disulphide bonds.

The amino acid composition of EHL is given in Table 4. The lectin is rich in asparagine/aspartic acid $(13.53 \mathrm{~mol} / 100 \mathrm{~mol})$, glutamine/glutamic acid $(10.57 \mathrm{~mol} / 100 \mathrm{~mol})$ and leucine $(9.41 \mathrm{~mol} / 100 \mathrm{~mol})$, but contains little methionine and cysteine. It contains also $5 \%$ covalently bound carbohydrate. No amino sugars could be detected by the amino acid analyser. 


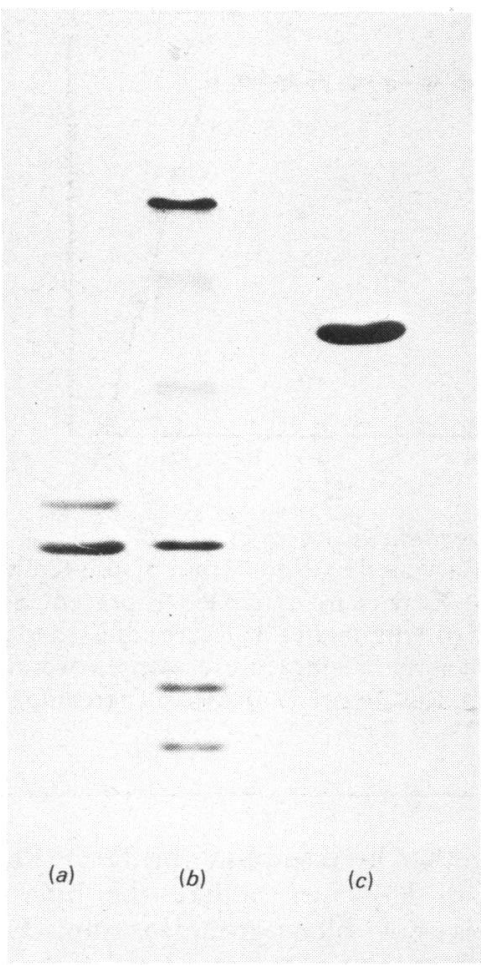

Fig. 2. Sodium dodecyl sulphate/polyacrylamide-gel electrophoresis of purified $E H L$ in the presence $(a)$ and in the absence (c) of 2\% 2-mercaptoethanol

For experimental details see the text. $M_{\mathrm{r}}$ reference proteins $(b)$ were lysozyme $\left(M_{\mathrm{r}} 14300\right)$, soya-bean trypsin inhibitor $\left(M_{\mathrm{r}} 21000\right)$, carbonic anhydrase $\left(M_{\mathrm{r}} 30000\right)$, ovalbumin $\left(M_{\mathrm{r}} 45000\right)$, bovine serum albumin $\left(M_{\mathrm{r}} 67000\right)$ and phosphorylase $b\left(M_{\mathrm{r}}\right.$ 94000). Gels were stained with Coomassie Brilliant Blue.

\section{Agglutination properties of EHL}

Hapten inhibition assays indicated that crude extract and purified EHL exhibit the same carbohydrate-binding specificity (Table 3 ) and preferential agglutination of blood-group-O erthyrocytes. Indeed, the specific agglutination activity of EHL is 10 -fold lower with group-A or group-B erythrocytes (Table 2). Moreover, trypsin-treated erythrocytes (of all three blood groups) were 100 times more sensitive to EHL than were untreated cells (Table 2). Besides human erythrocytes, EHL also agglutinates rabbit erythrocytes. Minimal lectin concentrations required for agglutination of untreated and trypsin-treated rabbit erythrocytes were $0.2 \mu \mathrm{g} / \mathrm{ml}$ and $3 \mu \mathrm{g} / \mathrm{ml}$ respectively.

\section{Stability of EHL under different conditions}

The stability of EHL was investigated under different conditions of temperature, $\mathrm{pH}$ and salt
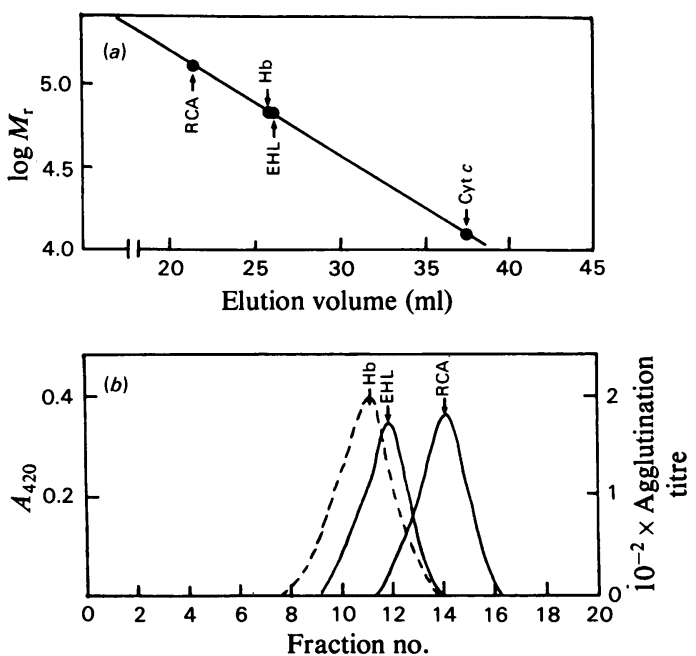

Fig. 3. Sephadex G-100 gel filtration (a) and sucrosedensity-gradient centrifugation (b) of EHL

(a) To avoid interactions between EHL and the Sephadex matrix (which result in a retarded elution of the lectin), gel filtration was done in $15 \mathrm{~mm}$ ethylenediamine, $\mathrm{pH} 10.5$, under which condition EHL has no sugar-binding activity. Column dimensions were $1.4 \mathrm{~cm} \times 28 \mathrm{~cm} . M_{\mathrm{r}}$ marker proteins were Ricinus communis agglutinin (RCA, $M_{\mathrm{r}}$ 120000), haemoglobin (Hb, $\left.M_{\mathrm{r}} 65000\right)$ and cytochrome $c$ (Cyt $c, M_{\mathrm{r}}$ 12400). (b) EHL was centrifuged in a linear $12-38 \%(\mathrm{w} / \mathrm{v})$ sucrose gradient (in PBS) at $2^{\circ} \mathrm{C}$ for $20 \mathrm{~h}$ at $50000 \mathrm{rev} . / \mathrm{min}$ in a Beckman SW 50.1 rotor. Gradients were fractionated into $0.2 \mathrm{ml}$ portions with an ISCO density-gradient fractionator and assayed for agglutination activity $(-)$ and $A_{420}$ (--). Ricinus communis agglutinin (RCA, $M_{\mathrm{r}}$ $120000)$ and haemoglobin $\left(\mathrm{Hb}, M_{\mathrm{r}} 65000\right)$ were used as $M_{\mathrm{r}}$ markers.

concentration. EHL was stable over the $\mathrm{pH}$ range 2-12 (Fig. $4 b$ ), and it was not inactivated by $\mathrm{NaCl}$ at concentrations up to $5 \mathrm{M}$. However, EHL is rather sensitive to heat. Indeed, above $30^{\circ} \mathrm{C}$ its agglutination activity is progressively diminished (Fig. 4a). Total loss of activity was observed upon heating at $70^{\circ} \mathrm{C}$.

\section{Discussion}

Winter-aconite tubers contain considerable amounts of an $\mathrm{N}$-acetylgalactosamine-specific lectin, which can readily be isolated by affinity chromatography on fetuin-agarose. Purified EHL has been characterized and appears to be a glycoprotein composed of two non-identical subunits of $M_{\mathrm{r}} 30000$ and 32000 held together by disulphide bonds. Since EHL is the first lectin to be isolated from a species of the family Ranunculaceae, no

Vol. 227 

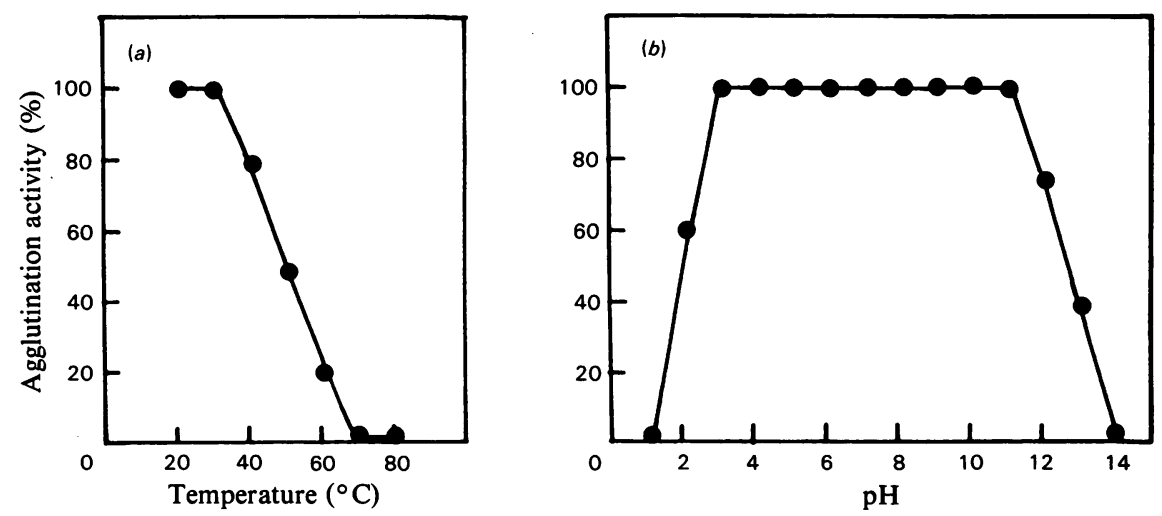

Fig. 4. Heat-stability (a) and pH-stability (b) of the agglutination activity of EHL

(a) Portions of an EHL solution $(0.1 \mathrm{mg} / \mathrm{ml}$ in PBS) were heated in a water bath for $3 \mathrm{~min}$ at the temperatures indicated, quenched cold in ice and assayed for agglutination activity. Results are expressed as percentages of the control (which was kept at $20^{\circ} \mathrm{C}$ ) value. (b) Portions of an EHL solution $(0.1 \mathrm{mg} / \mathrm{ml}$ in PBS) were adjusted to different $\mathrm{pH}$ values (by adding $0.1 \mathrm{M}-\mathrm{HCl}$ or $0.1 \mathrm{M}-\mathrm{NaOH}$ ). After being left for $1 \mathrm{~h}$ at room temperature, samples were adjusted to $0.2 \mathrm{M}$-Tris/ $\mathrm{HCl}$ buffer, $\mathrm{pH} 7.8$, and assayed for agglutination activity. Results are expressed as percentages of the control (samples kept in PBS) value.

Table 4. Amino acid composition of EHL

Amino acid composition

\begin{tabular}{lcc} 
Amino acid & (mol/100 mol) & (residues/molecule* \\
\hline Asp & 13.53 & 71 \\
Thr & 6.31 & 33 \\
Ser & 7.34 & 9 \\
Glu & 10.57 & 55 \\
Pro & 4.64 & 24 \\
Gly & 7.22 & 48 \\
Ala & 6.44 & 34 \\
Val & 5.54 & 29 \\
Met & 1.03 & 5 \\
Ile & 6.96 & 37 \\
Leu & 9.41 & 49 \\
Tyr & 3.35 & 18 \\
Phe & 3.22 & 17 \\
His & 1.42 & 7 \\
Lys & 1.03 & 5 \\
Arg & 7.09 & 37 \\
Trp & 2.45 & 13 \\
Cys & 2.45 & 13
\end{tabular}

* Expressed as the number of residues per molecule, assuming an $M_{\mathrm{r}}$ of 59000 (exclusive of carbohydrates).

comparison can be made with lectins from related species. Moreover, the winter-aconite lectin differs from previously described phytohemagglutinins. Indeed, EHL resembles only one plant lectin with respect to its molecular structure and sugarbinding specificity, namely that from bryony (Bryonia dioica) root stocks (which is also an $\mathrm{N}$ acetylgalactosamine-specific lectin composed of two non-identical subunits of $M_{\mathrm{r}} 30000$ and 32000 held together by disulphide bridges) (Peumans et al., 1984). However, unlike the bryony lectin, which is not blood-group-specific, EHL preferentially agglutinates group-O erythrocytes. In addition, the specific agglutination activity of the winter-aconite lectin is 20 times higher than that of the bryony lectin. Besides differences in agglutination properties, EHL and bryony lectin differ also with respect to their abundance and distribution over the plant. Whereas the bryony lectin occurs in all vegetative tissues and represents only $0.4 \%$ of the total protein in the root stocks (Peumans et al., 1984), EHL occurs exclusively in the root tubers, where it represents up to $3 \%$ of the total soluble protein.

Although EHL agglutinates preferentially blood-group-O erythrocytes, it cannot be classified with other anti-O plant lectins. Indeed, whereas the agglutinins from seeds of Lotus tetragonobulus (Asparagus pea) (Pereira \& Kabat, 1974) and Ulex europeus (gorse) (Pereira et al., 1979) exhibit specificity towards fucose and the Cytisus sessifolius (Matsumoto \& Osawa, 1974) and Laburnum alpinum (Matsumoto \& Osawa, 1971) seed lectins are best inhibited by $N N^{\prime}$-diacetylchitobiose, EHL is an $\mathrm{N}$-acetylgalactosamine-specific lectin.

The presence of high concentrations of lectin in a typical vegetative storage tissue such as winteraconite root tubers leaves intriguing questions about its physiological role. At present, only speculations can be made. It might be possible, however, that the function of (abundant) lectin in these vegetative storage tissues is similar to that of the (abundant) agglutinins in storage organs of seeds (e.g. cotyledons of legume seeds). 
This work is supported in part by grants from the National Fund for Scientific Research (Belgium), of which W. J. P. is a Research Associate. B. P. C. acknowledges the receipt of a Fellowship of the Belgian Instituut tot Aanmoediging van het Wetenschappelijk Onderzoek in Nijverheid en Landbouw.

\section{References}

Allen, A. K. (1979) Biochem. J. 183, 133-137

Allen, A. K., Desai, N. N., Neuberger, A. \& Creeth, J. M. (1978) Biochem. J. 171, 665-674

Broekaert, W. F., Nsimba-Lubaki, M., Peeters, B. \& Peumans, W. J. (1984) Biochem. J. 221, 163-169

Dubois, M., Gilles, K. A., Hamilton, J. K., Rebers, P. A. \& Smith, F. (1956) Anal. Chem. 28, 350-356
Goldstein, I. J. \& Hayes, C. E. (1978) Adv. Carbohydr. Chem. Biochem. 35, 127-340

Horejsi, V., Haskovec, C. \& Kocourek, J. (1978) Biochim. Biophys. Acta 532, 98-104

Kilpatrick, D. C. (1980) Biochem. J. 185, 269-272

Laemmli, U. K. (1971) Nature (London) 227, 680-685

Lowry, O. H., Rosebrough, N. J., Farr, A. L. \& Randall, R. J. (1951) J. Biol. Chem. 193, 265-275

Matsumoto, I. \& Osawa, T. (1971) Vox Sang. 21, 548-557

Matsumoto, I. \& Osawa, T. (1974) Biochemistry 13, 582588

Pereira, M. E. A. \& Kabat, E. A. (1974) Biochemistry 13, 3184-3192

Pereira, M. E. A., Gruezo, F. \& Kabat, E. A. (1979) Arch. Biochem. Biophys. 194, 511-525

Peumans, W. J., Nsimba-Lubaki, M., Carlier, A. R. \& Van Driessche, E. (1984) Planta 160, 222-228

Sabnis, D. D. \& Hart, J. W. (1978) Planta 142, 97-101

Waxdal, M. J. (1974) Biochemistry 13, 3671-3676 